\title{
Estudo Longitudinal, Bioquímico e Histoquímico, de Placentas de Ratas Diabéticas: Relação com a Macrossomia e o Retardo de Crescimento Intra-uterino*
}

Biochemical and Histochemical Longitudinal Analysis of Placentas of Diabetic Rats: Relationship with Macrosomatia and Intrauterine Growth Retardation

Iracema de Mattos Paranhos Calderon, Marilza Vieira Cunha Rudge, Maria Delgi Ramos, José Carlos Peraçoli

\begin{abstract}
RESUMO
Objetivo: o estudo longitudinal, entre o $18^{\circ}$ e o $21^{\circ}$ dias de prenhez, das alterações bioquimicas e histoquímicas das placentas de ratas diabéticas, cujos fetos tiveram macrossomia e retardo de crescimento intra-uterino (CIUR).

Material e Método: usando modelo experimental em ratas, foram estudados 3 grupos: controle, diabete moderado e grave. A prenhez foi resolvida por cesárea no $18^{\circ}$ ou no $21^{\circ}$ dia. Compararam-se as glicemias materna e fetal; a incidencia de recém-nascidos (RN) de peso pequeno (PIP), adequado (AIP) e grande (GIP) para tempo de prenhez; peso, indice e conteúdo de DNA, RNA e proteínas placentários e quantidade de glicogênio na superficie de trocas materno-fetais.

Resultados: no diabete moderado houve maior proporção de RN-GIP com placentas ricas em DNA e diminuição progressiva de glicogênio em suas membranas no final da prenhez. No diabete grave houve predominio de RN-GIP e as placentas exibiram menor conteúdo de $D N A$, sintese aumentada de RNA e tendência a maior produção protéica, com manutenção dos depósitos de glicogênio.

Conclusões: concluiu-se que, entre o $18^{\circ}$ e o $21^{\circ}$ dias, os desvios do crescimento fetal no diabete materno, moderado e grave relacionam-se a alterações placentárias distintas. No moderado há apenas hiperplasia celular, com desaparecimento do glicogênio no final da prenhez. No grave, a superficie de trocas materno-fetais é mais espessada e, além de hiperplasia, há hipertrofia das células, com manutenção dos estoques placentários de glicogênio.
\end{abstract}

PALAVRAS-CHAVE: Diabete e gravidez. Macrossomia - CIUR. Placenta: alterações.

Disciplina Obstetrícia - Departamento de Ginecologia e Obstetricia

Faculdade de Medicina de Botucatu - UNESP

Correspondência:

Iracema de Mattos Paranhos Calderon

Rua Atílio Losi, 226 - Jardim Paraíso

18610-260 - Botucatu - SP

Fone/Fax: (014) 822-2836

* Prêmio Domingos Deláscio na III Jornada Paulista de Ginecologia e Obstetrícia - SOGESP - 1993

\section{Introdução}

A macrossomia e o retardo de crescimento intra-uterino (CIUR) são observados entre os casos com diabete mal controlado, os de longa evolução e nos que apresentam alterações vasculares ${ }^{6}$.

A literatura é controversa a respeito da reprodução experimental do feto macrossômico nas 
gestantes diabéticas. Um modelo experimental em ratas para estudo do binômio diabete e gravidez revelou desvios do crescimento fetal, relacionados à intensidade do diabete materno. A hiperglicemia moderada induziu a macrossomia e a grave $\mathrm{o}$ retardo de crescimento fetal ${ }^{2}$.

As placentas nas gestações humanas complicadas pelo diabete são maiores que o normal e apresentam alterações estruturais que interferem no crescimento fetal ${ }^{20}$. Na prenhez de ratas com diabete grave, a placenta é grande e os fetos pequenos em relação ao grupo controle ${ }^{2,5}$. No diabete moderado, a placenta também está aumentada, mas os fetos são grandes em relação ao grupo controle ${ }^{2}$.

Esta discrepância entre o tamanho fetal e placentário é encontrada em várias outras condições, caracterizadas pelo menor aporte de oxigênio ao feto. Nestas condições, a placentomegalia é explicada por mecanismo de compensação que possibilitaria, graças ao crescimento, maior superficie de troca maternofetal. É o que poderia acontecer na associação do diabete e gravidez, pelos efeitos da doença na arquitetura vascular placentária ${ }^{1}$.

As alterações bioquímicas associadas a anomalias estruturais caracterizam um retardo no amadurecimento das placentas. Em ratas diabéticas, a sintese de DNA placentário continua até o $18^{\circ}$ e $19^{\circ}$ dias de prenhez, dois a três dias a mais em relação à estabilização do total de DNA nas placentas de ratas não-diabéticas ${ }^{5}$. Estudos com microscopia eletrônica confirmam depósito de glicogênio na superfície placentária em ratas diabéticas, sugerindo, também, imaturidade do órgão ${ }^{6}$. Pela microscopia óptica, a presença de espessamento da membrana nas regiões de trocas materno-fetais e a presença de células trofoblásticas remanescentes nas placentas de ratas diabéticas denotam imaturidade, ou seja, um órgão menos eficiente para garantir o desenvolvimento fetal ${ }^{2}$.

A literatura não explica porque as alterações placentárias observadas em microscopia óptica, embora semelhantes nas ratas com diabete moderado e grave, levam a resultados fetais opostos. A resposta pode estar na quantidade diferente de glicogênio depositada na superficie de troca e na composição bioquímica das placentas no diabete moderado e grave.

Em vista da ocorrência de tais alterações anatomopatológicas, semelhantes no diabete moderado e grave, associando macrossomia e retardo de crescimento intra-uterino, planejamos este estudo de forma longitudinal, entre o $18^{\circ}$ e o $21^{\circ}$ dia de prenhez, do peso e índice placentários e das alterações bioquímicas e histoquimicas das placentas de ratas com diabete moderado e grave.

\section{Material e Método}

Foram estudados três grupos experimentais:

a) controle: composto de 20 ratas não-diabéticas e 20 ninhadas;

b) diabete $\mathrm{M}$ : (diabete moderado) grupo composto de 20 ratas com glicemia na prenhez entre 120 e $200 \mathrm{mg} / \mathrm{dl}$ e 20 ninhadas;

c) diabete G: diabete grave, composto de 20 ratas com glicemia na prenhez superior a $200 \mathrm{mg} / \mathrm{dl}$ e 20 ninhadas.

Adotou-se seqüência experimental para estudo de diabete e prenhez em ratas Wistar padronizada por Calderon ${ }^{2}$. Em cada grupo experimental, metade das ratas teve a prenhez resolvida, por cesárea, no $18^{\circ}$ dia e, na outra metade, a prenhez se estendeu até o termo ( $\left.21^{\circ} \mathrm{dia}\right)$.

Os recém-nascidos foram separados das placentas por técnica de arrancamento, identificados e pesados. A seguir, foram decapitados e colhido "pool" de sangue de toda ninhada para determinação da glicemia plasmática por método enzimático. Este procedimento só foi possível no $21^{\circ}$ dia, pois no $18^{\circ}$ dia de prenhez a quantidade de sangue dos filhotes é insuficiente para análise da glicemia, tanto por método enzimático, como por fitas-reagente. O peso dos recém-nascidos foi classificado em pequeno (PIP), adequado (AIP) e grande (GIP) para tempo de prenhez, considerandose a média e o desvio-padrão do grupo controle ${ }^{2}$.

O estudo das placentas baseou-se no cálculo do peso e índice placentários, que é a relação entre o peso da placenta e o peso fetal, na análise histoquímica, que evidencia os depósitos de glicogênio na superfície de trocas, pela reação de PAS (técnica padronizada no Laboratório de Anatomopatologia da Faculdade de Medicina de Botucatu - UNESP) e na análise bioquímica dos conteúdos de $\mathrm{DNA}^{8,13}$ e proteinas ${ }^{11}$. Tais observações foram realizadas no $18^{\circ}$ e $21^{\circ}$ dias de prenhez.

Os resultados quantitativos foram submetidos a testes estatísticos em que se empregou análise de variância, pelo teste $\mathrm{F}$, seguida dos testes de Tukey para amostras nãodependentes $\mathrm{e}$ " $\mathrm{t}$ " para amostras dependentes. O teste do $\chi^{2}$ foi usado para comparar a incidência das classes de recém-nascidos, adotando-se $5 \%$ como limite de significância ${ }^{21}$. 


\section{Resultados}

Na Figura 1 observa-se a evolução da glicemia materna, durante a prenhez: as ratas do grupo controle tiveram queda entre o $1^{\circ}$ e o $14^{\circ}$ dias, com aumento progressivo até o $21^{\circ}$ dia, dentro da faixa de normoglicemia. As ratas com diabete moderado também apresentaram diminuição da glicemia entre o $1^{\circ}$ e o $14^{\circ}$ dias, com aumento após o $18^{\circ}$ dia. No diabete grave, os niveis glicêmicos maternos foram constantes até o $18^{\circ}$ dia, com descompensação após este período. A glicemia dos filhotes ao nascimento, na prenhez de termo $\left(21^{\circ}\right.$ dia), reflete os niveis glicêmicos intra-uterinos (Figura 2). No $18^{\circ}$ dia, o grupo controle teve distribuição normal entre recém-nascidos de peso adequado (AIP), pequeno (PIP) e grande (GIP) para tempo de prenhez; esta distribuição se manteve no diabete moderado e, entre as ratas com diabete grave, houve predomínio de recém-nascidos PIP. No $21^{\circ}$ dia o diabete moderado foi modelo de macrossomia e o grave continuou sendo modelo de CIUR (Figura 3).

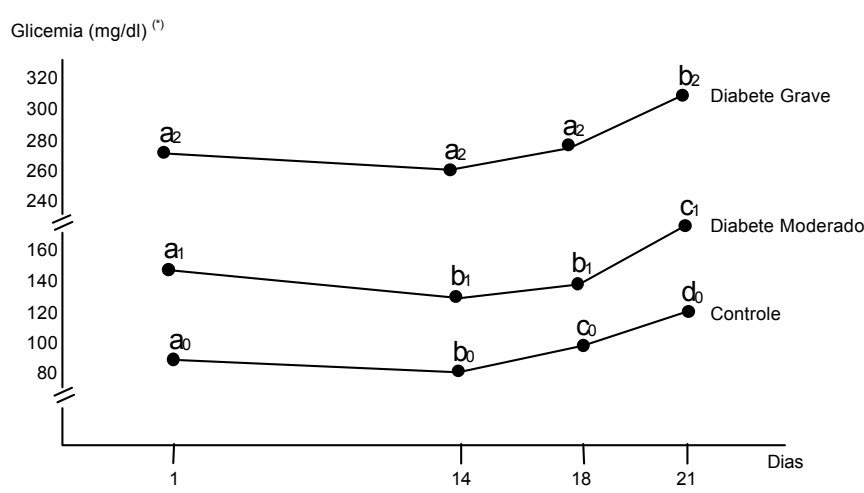

(*) As médias dos grupos experimentais, seguidas da mesma letra e respectivo indice, não diferem entre si ao nível de $5 \%$ de probabilidade pelo teste " $t$ " para amostras dependentes.

Figura 1 - Evolução da glicemia materna na prenhez de ratas dos grupos controle e diabéticos, moderado e grave.

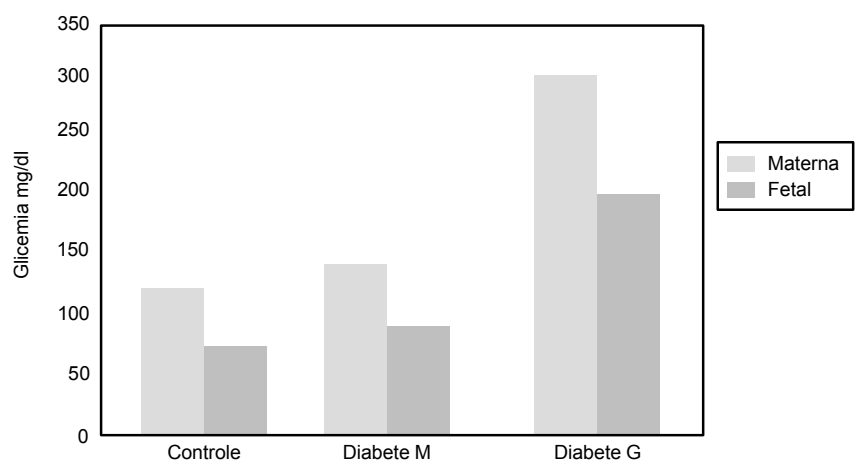

Figura 2 - Níveis glicêmicos, maternos e fetais, no $21^{\circ}$ dia da prenhez nos grupos de ratas controle e diabéticos, moderado $(\mathrm{M})$ e grave $(\mathrm{G})$.
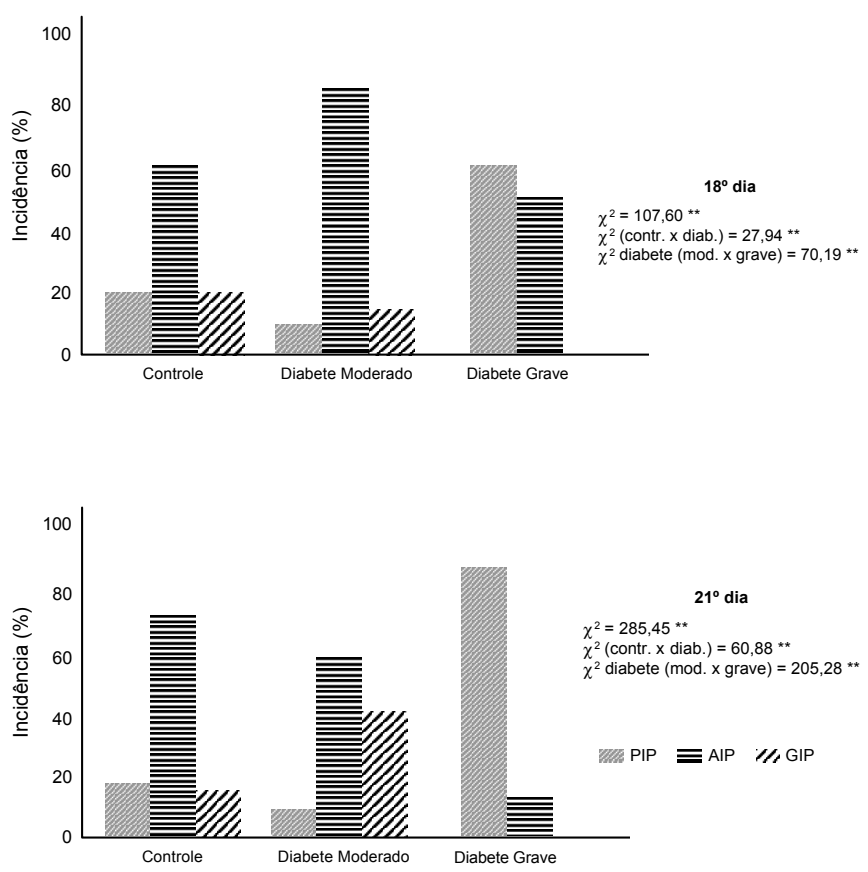

** = Significativo ao nível de $1 \%$ de probabilidade pelo teste do qui-quadrado $\left(\chi^{2}\right)$.

Figura 3 - Incidência (\%) de recém-nascidos classificados entre os de peso pequeno (PIP), adequado (AIP) e grande (GIP) para a idade no $18^{\circ}$ e $21^{\circ}$ dias de prenhez, nos grupos controle e diabéticos, moderado e grave.

O peso dos fetos do grupo diabete grave foi menor no $18^{\circ}$ dia e no $21^{\circ}$ dia da prenhez. A placentomegalia foi característica dos grupos diabéticos desde o $18^{\circ}$ dia da prenhez e o índice placentário $(\mathrm{PP} / \mathrm{FF})$ foi sempre maior no diabete grave (Tabela 1 ).

O conteúdo de DNA placentário foi maior no $21^{\circ}$ dia da prenhez de ratas diabéticas e o de RNA foi menor apenas no grupo diabete moderado no $21^{\circ}$ dia da prenhez. As proteínas estavam aumentadas no $18^{\circ}$ dia no grupo diabete moderado e no $21^{\circ}$ dia no grupo diabete grave (Tabela 2 ).

No $18^{\circ}$ dia as placentas de todos os grupos exibiram reação de PAS positiva (Figura 4A, B e C). No $21^{\circ}$ dia, as placentas dos grupos controle e diabete moderado apresentaram reação de PAS negativa e nas do grupo diabete grave, a reação de PAS era fortemente positiva (Figura 5A, B e C).

Os cortes histológicos das placentas do grupo controle foram caracterizados por uma camada esponjosa frouxa, de aspecto rendilhado; condutos vásculo-fetais de parede endotelial delgada, perfeitamente justapostos às lacunas maternas, determinando adelgaçamento da superficie de trocas materno-fetais; poucas células plasmodiais 
(citotrofoblasto) se projetavam na luz das lacunas maternas (EIV na placenta humana). Em contraposição, as placentas dos grupos diabéticos, moderado e grave, apresentavam camada esponjosa densa, de aspecto compacto; condutos vásculo-fetais de parede endotelial espessa, denotando maior quantidade de tecido interposto às lacunas maternas; células plasmodiais em maior número e mais proeminentes na luz das lacunas maternas (Figuras 4A, B, C e 5A, B, C).

Tabela 1 - Pesos fetais e placentários e índice placentário no $18^{\circ}$ e $21^{\circ}$ dias da prenhez nos grupos de ratas controle e diabéticos, moderado (M) e grave $(G)$. Médias $(\overline{\times})$ e desvio padrão (DP).

\begin{tabular}{|c|c|c|c|c|c|c|c|}
\hline \multicolumn{2}{|c|}{$\begin{array}{l}\text { Grupos } \\
\text { Experimentais }\end{array}$} & \multicolumn{2}{|c|}{ Peso (g) $(*)$} & $\begin{array}{l}\text { Índice placentário }(*) \\
\qquad(\mathrm{PP} / \mathrm{PF})\end{array}$ & \multicolumn{2}{|c|}{$\operatorname{Peso}(\mathrm{g})(*)$} & $\begin{array}{c}\text { Índice placentário }(*) \\
(\mathrm{PP} / \mathrm{PF})\end{array}$ \\
\hline Controle & DP & 0,120 & 0,039 & 0,01 & 0,117 & 0,058 & 0,01 \\
\hline \multirow[t]{2}{*}{ Diabete M } & $\bar{x}$ & $1,465 \mathbf{a}_{0}$ & $0,504 \mathbf{a}_{1} \mathbf{b}_{1}$ & $0,27 \mathbf{a}_{2}$ & $5,376 \mathbf{a}_{0}$ & $0,504 \mathbf{a}_{1} \mathbf{b}_{1}$ & $0,09 \mathbf{a}_{2}$ \\
\hline & DP & 0,072 & 0,070 & 0,04 & 0,181 & 0,070 & 0,01 \\
\hline
\end{tabular}

(*) Médias dos grupos experimentais, seguidas da mesma letra e indice, não diferem entre si ao nível de 5\% de probabilidade pelo teste de Tukey, para cada tempo de prenhez.

Tabela 2 - Composição das placentas quanto ao seu conteúdo de DNA, RNA e proteínas, no $18^{\circ}$ e $21^{\circ}$ dias de prenhez, nos grupos de ratas controle e diabéticos, moderado (M) e grave (G). Médias $(\overline{\times})$ e desvio padrão (DP).

\section{Conteúdo/Total placenta (*)}

\begin{tabular}{|c|c|c|c|c|c|c|c|}
\hline \multirow{2}{*}{$\begin{array}{l}\text { Grupos } \\
\text { Experimentais }\end{array}$} & & \multicolumn{2}{|c|}{ DNA $(\mu \mathrm{g} / \mathrm{g})$} & \multicolumn{2}{|c|}{ RNA $(\mu \mathrm{g} / \mathrm{g})$} & \multicolumn{2}{|c|}{ proteínas (mg/g) } \\
\hline & & $18^{\circ}$ & $21^{\circ}$ & $18^{\circ}$ & $21^{\circ}$ & $18^{\circ}$ & $21^{\circ}$ \\
\hline Controle & DP & 0,13 & 0,21 & 0,39 & 0,20 & 0,03 & 0,03 \\
\hline \multirow[t]{2}{*}{ Diabete M } & $\bar{x}$ & $0,85 \mathbf{a}_{0}$ & $1,28 \mathbf{b}_{1}$ & $1,56 \mathbf{a}_{0}$ & $1,10 \mathbf{b}_{1}$ & $0,29 \mathbf{b}_{0}$ & $0,27 \mathbf{a}_{\mathbf{1}}$ \\
\hline & DP & 0,27 & 0,52 & 0,52 & 0,28 & 0,05 & 0,07 \\
\hline
\end{tabular}

(*) Médias dos grupos experimentais, seguidas da mesma letra e índice, não diferem entre si ao nível de 5\% de probabilidade pelo teste de Tukey, para cada tempo de prenhez. 


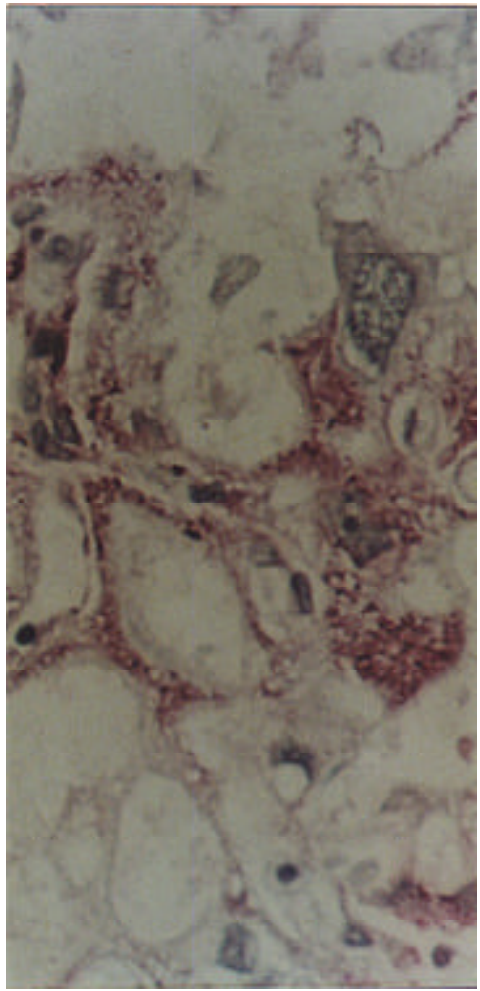

Figura 4A - Placenta do grupo controle na prenhez de 18 dias: reação de PAS positiva (PAS $40 \times 1,25 \times 10$ )

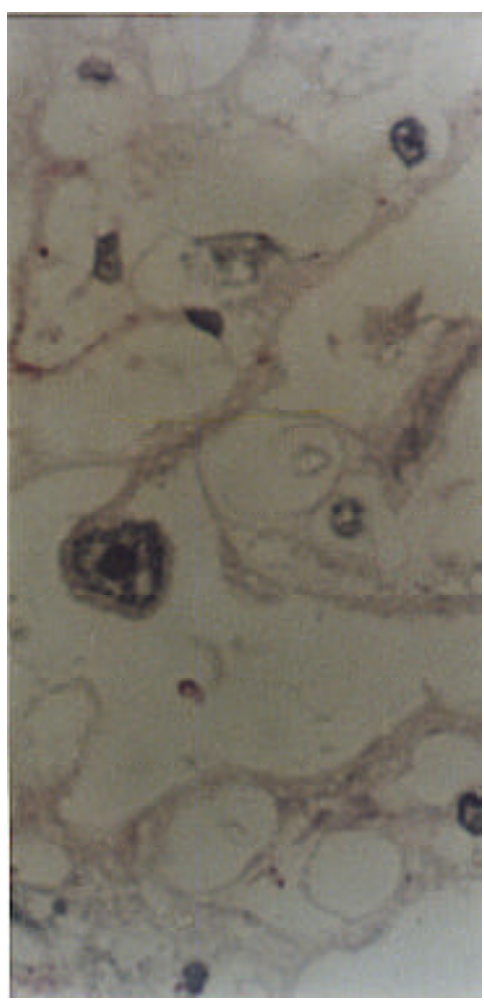

Figura 5A - Placenta do grupo controle na prenhez de 21 dias: reação de PAS negativa e membrana placentária adelgaçada (PAS $40 \times 1,25 \times 10$ ).

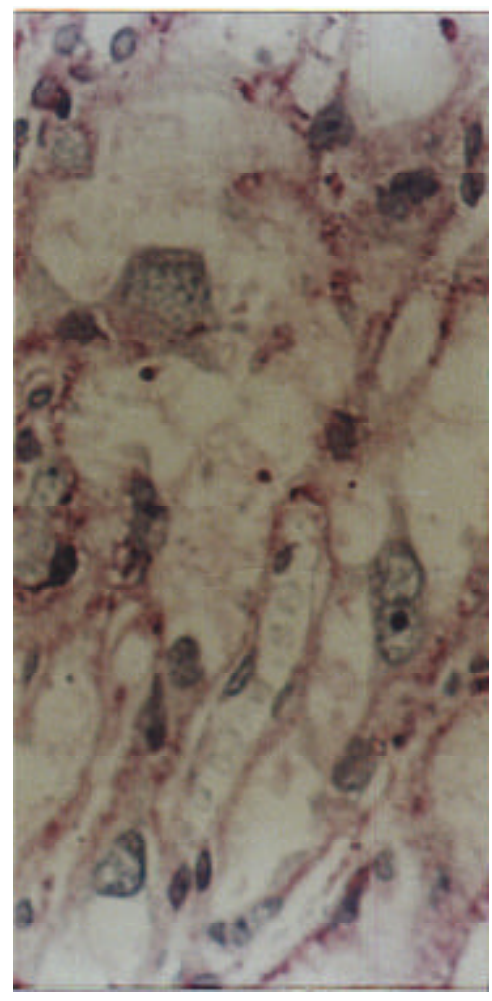

Figura 4B - Placenta do grupo diabete moderado na prenhez de 18 dias: reação de PAS positiva (PAS $40 \times 1,25 \times 10$ )

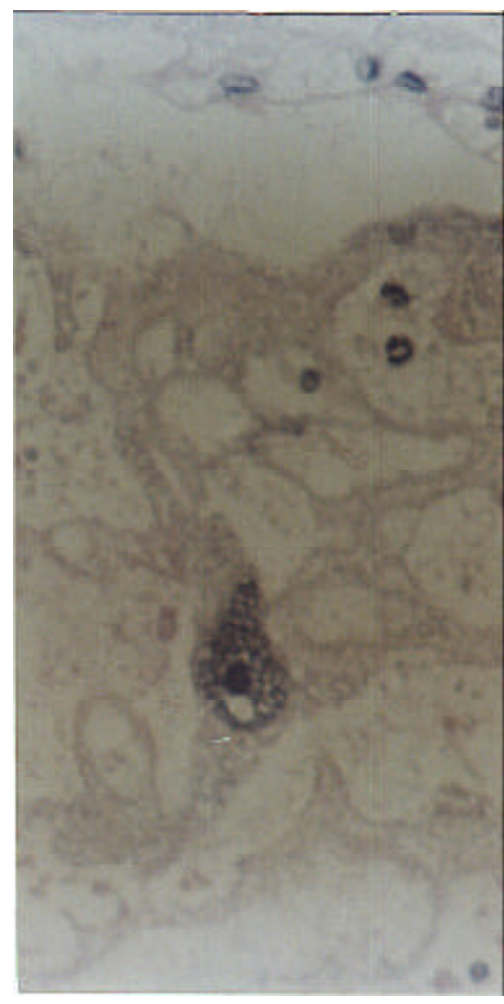

Figura 5B - Placenta do grupo diabete moderado na prenhez de 21 dias: reação de PAS negativa com espessamento da membrana placentária (PAS 40 x 1,25 $\mathrm{x}$ 10).

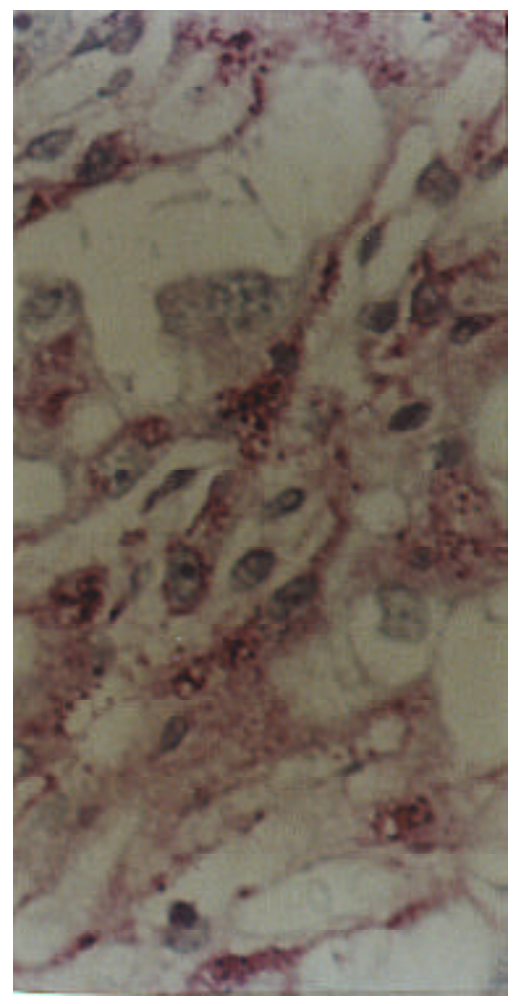

Figura 4C - Placenta do grupo diabete grave na prenhez de 18 dias: reação de PAS positiva (PAS $40 \times 1,25 \times 10$ )

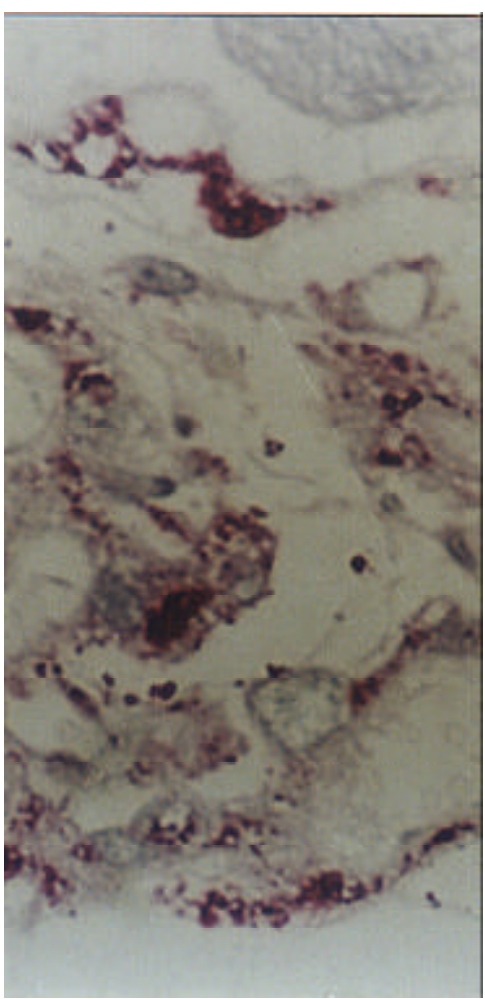

Figura $5 \mathrm{C}$ - Placenta do grupo diabete grave na prenhez de 21 dias: reação de PAS fortemente positiva e membrana placentária bastante espessada (PAS $40 \times 1,25 \times 10$ ). 


\section{Discussão}

O crescimento fetal é mais intenso na segunda metade da gestação humana, o que corresponde na prenhez de ratas, ao intervalo entre o $14^{\circ}$ e o $21^{\circ}$ dias. O estudo dos desvios do crescimento fetal deve ter mais sucesso se restrito a este periodo da prenhez, caracterizado por elevação da glicemia materna, tanto no grupo de ratas controle como diabéticas. Entretanto, dificuldades técnicas, relacionadas à caracterização dos fetos e ao tamanho, impediram que o estudo fosse feito entre o $14^{\circ}$ e o $21^{\circ}$ dias, só sendo possivel entre o $18^{\circ}$ e o $21^{\circ}$ dias.

A glicemia materna refletiu-se sobre o feto e os niveis glicêmicos dos recém-nascidos confirmaram a normo e a hiperglicemia moderada e grave do meio intra-uterino. Estes aspectos foram descritos na literatura relacionando os efeitos do diabete materno sobre a evolução fetal nas gestações humanas ${ }^{15}$ e na prenhez de $\operatorname{ratas}^{2,16,18}$.

Um dos efeitos mais comuns da hiperglicemia materna é a macrossomia fetal. Tal característica é classicamente observada entre os filhos de mães diabéticas ${ }^{14}$ e explicada pela maior oferta de glicose ao meio intra-uterino, substrato que se traduz na principal fonte de energia para o desenvolvimento e crescimento fetal ${ }^{9,15}$. Entretanto, a reprodução do feto macrossômico em modelos experimentais de diabete e prenhez é sujeita a controvérsias na literatura. Alguns autores observaram peso fetal diminuído em relação ao grupo controle $e^{4,7,16}$, ao passo que outros consideraram a macrossomia característica do diabete experimental ${ }^{12,17}$.

Um modelo experimental em ratas, para estudo do binômio diabete e gravidez, revelou desvios do crescimento fetal relacionados à intensidade do diabete materno. A hiperglicemia materna moderada induziu a macrossomia e a grave, o retardo de crescimento fetal ${ }^{2}$. Os resultados deste experimento reforçaram a hipótese de que a hiperglicemia materna moderada determina maior proporção de recém-nascidos grandes (GIP) e que a hiperglicemia grave se relaciona com recémnascidos pequenos (PIP) para tempo de prenhez. Mostraram também que estas alterações ocorreram no final da prenhez, ou seja, a partir do $18^{\circ}$ dia, quando o crescimento fetal é mais acentuado ${ }^{3}$. No diabete moderado, houve diminuição da incidência de fetos com peso pequeno e adequado e elevou-se a de fetos macrossômicos. Nos nossos grupos experimentais de diabete grave, observou-se aumento do índice de retardo de crescimento, à custa de diminuição dos recém-nascidos de peso adequado, e a macrossomia não se manifestou.

O CIUR na prenhez de ratas normais é secundário à insuficiência da placenta, caracterizada por diminuição do peso e do fluxo placentários ${ }^{19}$. Entretanto, na prenhez complicada pelo diabete, tanto o CIUR como a macrossomia se associam à placentomegalia ${ }^{10,16}$, observação comprovada também neste experimento. Se a placentomegalia se relacionou aos dois extremos do desenvolvimento fetal, não deve ser apenas o peso deste órgão o responsável pelos distúrbios do crescimento do feto.

Analisando a função placentária pelo índice placentário, relação entre o peso da placenta e o peso fetal, pode-se afirmar que existe disfunção placentária apenas no diabete grave. Os índices placentários no diabete moderado foram superponíveis aos do controle, no $18^{\circ}$ e no $21^{\circ}$ dias e, no diabete grave, a disfunção da placenta se manifestou no $18^{\circ}$ dia, intensificando-se ao termo da prenhez. Estes resultados apontam insuficiência da placenta em garantir as trocas materno-fetais, proporcional à intensidade do diabete, como fator importante na gênese dos desvios do crescimento fetal. Apesar dos pesos das placentas serem equivalentes nos grupos diabéticos, o indice placentário revela respostas diferenciadas ao estímulo hiperglicêmico moderado e grave. A falta de correlação histopatológica para estes achados sugere que outros distúrbios devem estar presentes e precisam ser investigados.

Os parâmetros avaliados neste experimento confirmam a influência da glicemia materna na determinação das características placentárias distintas em relação ao conteúdo celular (DNA, RNA e proteínas) e depósito de glicogênio ${ }^{6}$, que interferem com a evolução de peso dos recémnascidos no período de máximo desenvolvimento. Observou-se que no grupo controle a glicemia materna manteve-se dentro dos limites de normalidade. Esta normoglicemia permitiu que o desenvolvimento placentário fosse adequado, ou seja, o crescimento celular foi interrompido no $18^{\circ}$ dia, facilitando as trocas materno-fetais. Os conteúdos de DNA, RNA e proteínas mantiveramse estáveis e o glicogênio depositado nas membranas placentárias foi desaparecendo gradativamente do $18^{\circ}$ ao $21^{\circ}$ dia, traduzindo especialização do órgão no sentido de garantir as necessidades fetais. Os recém-nascidos tiveram, em sua maioria, peso adequado e os desvios do crescimento, a macrossomia e o CIUR incidiram em proporções semelhantes e discretas.

No diabete moderado, a hiperglicemia materna interferiu com os desenvolvimentos placentário e fetal. Nessas placentas, a sintese de DNA continuou, de maneira acentuada, no final da prenhez, apesar da manutenção na produção de RNA e proteínas. Houve apenas hiperplasia 
celular que, associada ao aumento do depósito de glicogênio no $18^{\circ}$ dia e seu total desaparecimento no $21^{\circ}$ dia (Figuras $4 \mathrm{~B}$ e $5 \mathrm{~B}$ ), permitiu que a hiperglicemia materna se refletisse sobre o meio intra-uterino, proporcionando desenvolvimento fetal exagerado. A proporção de recém-nascidos macrossômicos foi maior no $21^{\circ}$ dia da prenhez, à custa da diminuição da incidência dos de peso adequado para a idade gestacional.

No diabete grave, a hiperglicemia materna grave alterou a maturação da placenta, caracterizando-a como insuficiente em sua função nutritiva, pela maior incidência de recém-nascidos pequenos para tempo de prenhez. Observou-se que, além da produção contínua de DNA, a síntese de RNA e proteínas foi mantida até o final da prenhez, ou seja, a hiperplasia e a hipertrofia celular, associadas à manutenção de glicogênio no $21^{\circ}$ dia (Figuras $4 \mathrm{C}$ e $5 \mathrm{C}$ ), tornaram a superficie de troca materno-fetal mais espessa e prejudicaram o desenvolvimento do feto. Em decorrência destas alterações, houve diminuição acentuada dos recémnascidos de peso adequado e manifestou-se o CIUR.

Fica evidenciado que, apesar do aspecto histopatológico semelhante entre placentas de ratas diabéticas, cujos recém-nascidos têm macrossomia ou retardo de crescimento, existem alterações bioquímicas e histoquimicas que explicam a ocorrência desses desvios do crescimento fetal com características diferentes.

\section{SUMMARY}

Purpose: placental alterations were evaluated in macrosomatia and fetal growth retardation in pregnancy complicated by diabetes. Three groups of rats, used as experimental models, were studied: control, moderate and severe diabetes.

Material and Method: cesarian sections were carried out on the 18th or 21st day of pregnancy. Maternal and fetal glycemia, newborn weight, placental weight, relationship between placental and fetal weight, DNA, RNA and protein contents and the glycogen deposited on placental membranes were analyzed.

Results: there was a higher number of macrosomic newborns in the moderate diabetes group, whose placentas were rich in DNA with progressive decrease of glycogen in their membranes towards the end of pregnancy. There was a predominance of small for date newborns in the severe diabetes group. Their placentas showed a small DNA proportion, an increase in $R N A$ synthesis and a tendency to higher protein production, with no change in the glycogen deposit.
Conclusions: we conclude that fetal growth deviation in moderate and severe maternal diabetes between the 18th and 21 st days of pregnancy is related to several placental alterations. In the moderate form there were only cellular hyperplasia and disappearance of placental glycogen at the end of pregnancy. In the severe diabetes group there was thickening of maternal-fetal membranes during this period. There was cellular hyperplasia and hypertrophy associated with the maintenance of glycogen reserves in the placental membranes.

KEY WORDS: Diabetic and pregnancy. MacrosomatiaIUGR. Placental alterations.

\section{Referências}

1. Benirschke K, Kaufmann P. The pathology of the human placenta. $3^{\text {rd }}$ ed. New York: SpringerVerlag; 1995. p. 486-9.

2. Calderon IMP. Modelo experimental em ratas para estudo do binômio diabete e gravidez. (Dissertação Mestrado). Faculdade de Medicina de Botucatu, UNESP; 1988.

3. Cunningham FG, MacDonald PC, Gant NF. The placenta and fetal membranes. In: - Williams Obstetrics. $20^{\text {th }}$ ed. Norwalk: Appleton $\&$ Lange; 1997. p. 39-65.

4. Eriksson UJ. Diabetes in pregnancy: retarded fetal growth, congenital malformations and fetomaternal concentrations of zinc, copper and manganese in the rat. J Nutr 1984; 114: 477-84.

5. Gewolb IH, Barrett C, Warshaw JB. Placental growth and glycogen metabolism in streptozotocin diabetic rats. Pediatr Res 1983; 17: 587-91.

6. Gewolb IH, Meridian W, Warshaw JB, Enders AC. Fine structural abnormalities of the placenta in diabetic rats. Diabetes 1986; 35: 1254-61.

7. Giavini E, Broccia ML, Prati M, Roversi GD, Vismara C. Effects of streptozotocin-induced diabetes on fetal development of the rat. Teratology 1986; 34: 81-8.

8. Giles KW, Myers A. An improved diphenylamine method for the estimation of deoxyribonucleic acid. Nature 1965; 206: 93.

9. Hollingsworth DR. Maternal metabolism in normal pregnancy and pregnancy complicated by diabetes mellitus. Clin Obstet Gynecol 1985; 28: 457-72.

10.Kervran A, Guillaume M, Jost A. The endocrine pancreas of the fetus from diabetic pregnant rat. Diabetologia 1978; 15: 387-93. 
11.Lowry OH, Rosenburgh NJ, Farr AL. Protein measurements with the Folin-phenol reagent. J Biol Chem 1951; 193: 265-75.

12.Mintz DH, Chez RA, Hutchinson DL. Subhuman primate pregnancy complicated by streptozotocininduced diabetes mellitus. J Clin Invest 1972; 51: 837-47.

13. Munro HN, Fleck A. The determination of nucleic acids. Methods Biochem Anal 1966; 14: 113-76.

14.Oh W. Neonatal care and long-term outcome on infants of diabetic mothers. In: Merkatz IR, Adam PAJ. The diabetic pregnancy: a perinatal perspective. New York: Grune \& Stratton; 1979. p. 195-205.

15.Pedersen J. A diabética grávida e seu recém-nascido: problemas e trtamento. São Paulo, Manole; 1979; 253p.

16.Pitkin RM, Van Orden DE. Fetal effects of maternal streptozotocin - diabetes. Endocrinology 1974; 94: 1247-53.
17.Pitkin RM, Plank CJ, Filer Jr LJ. Fetal and placental composition in experimental maternal diabetes. Proc Soc Exp Biol Med 1971; 138: 163-6.

18.Rudge MVC, Calderon IMP, Ramos MD, Rodrigues MAM. Diabetes and experimental pregnancy in rats: course of maternal blood glucose levels and its repercussions on the blood glucose levels and pancreas of newborn pups. Braz J Med Biol Res 1995; 28: 219-25.

19.Saintonge J, Rosso P. Placental blood flow and trasfer of nutrient analogs in large, average, and small guinea pig littermates. Pediatr Res 1981; 15: $152-6$.

20.Singer DB. The placenta in pregnancies complicated by diabetes mellitus. Perspect Pediatr Pathol 1984; 8: 199-212.

21.Snedecor GW, Cochran WG. Statistical methods. 6.ed. Ames: Iowa State University; 1974. 593p.

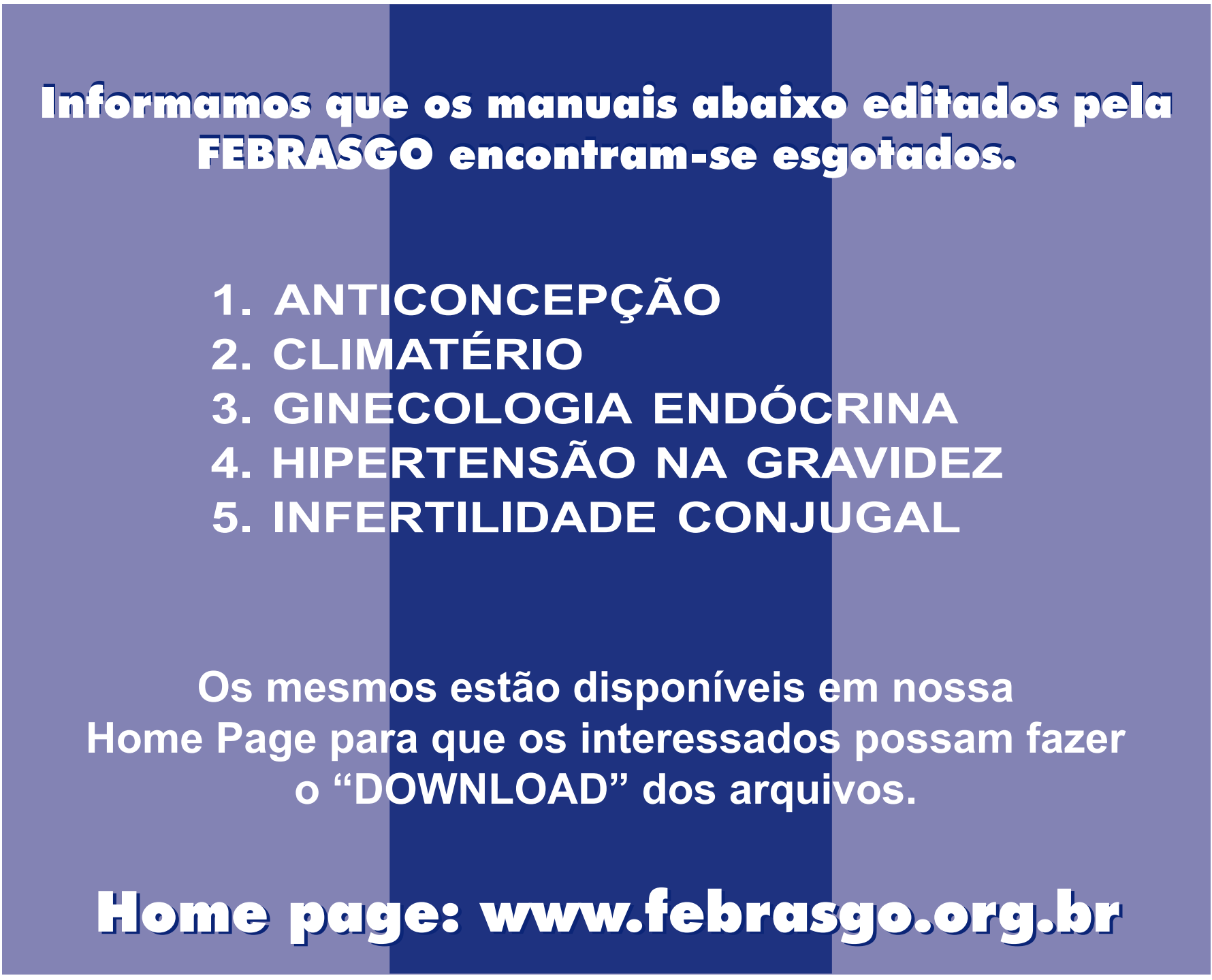

